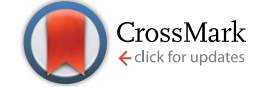

Cite this: RSC Adv., 2017, 7, 4039

Received 15th November 2016 Accepted 27th December 2016

DOI: 10.1039/c6ra26831e

www.rsc.org/advances

\section{Superhydrophobic silica aerogels reinforced with polyacrylonitrile fibers for adsorbing oil from water and oil mixtures $\uparrow$}

\author{
Mingjia Shi, Cunguo Tang, Xudong Yang, Junling Zhou, Fei Jia, Yuxiang Han \\ and Zhenyu Li*
}

\begin{abstract}
Silica aerogels are unique solids with extremely high porosity, transparency and low density. They make excellent adsorbing materials due to their high surface area and three-dimensional reticular structures. However, their fine structures and hydrophilic surfaces make them fragile and impractical for adsorbing oil from water and oil mixtures. To improve their mechanical properties, we incorporate small amounts of polyacrylonitrile fiber into the aerogels, prepared at relatively mild temperatures. Electron microscopy images and pore size distributions of the modified aerogels show that the silica aerogel had a cocontinuous porous structure. The aerogels were modified to be superhydrophobic, and the surface hydroxyl or alkoxy groups were converted to stable $-\mathrm{CH}_{3}$ groups with a contact angle as high as $169^{\circ}$. The oil adsorption capacity of the silica aerogels was calculated as $9.56 \mathrm{~g} / \mathrm{g}$. The sorption and desorption process could be repeated at least 100 times, indicating that silica aerogels are promising oil-absorbing materials.
\end{abstract}

\section{Introduction}

With a rapid increase in global energy demand, oil production has continued to grow from conventional and unconventional resources. Significant amounts of oil pollutants are generated during these processes. ${ }^{1-5}$ Discharging wastewater from these processes into the environment has become a significant concern for current oil production techniques such as fracking. Therefore, various techniques have been adopted to remove oil from water and oil mixtures, including adsorption, filtration, reverse osmosis, air flotation, biological processes, chemical coagulation, electro coagulation and electro flotation..$^{6-8}$ Among these techniques adsorption is the most common and most widely used due to its high efficiency, low cost, and wide adaptability. ${ }^{9-11}$ Conventional natural materials such as sawdust, zeolite and wool fiber have been extensively used for oil removal due to their porous structures and high surface area. ${ }^{12-14}$ However, the major drawback of these materials is that water and oil cannot be separately absorbed, and as such their adsorption efficiency is poor. As a result, there is an increasing need for the development of new porous materials to effectively adsorb oil from water.

Recently, silica aerogels with low density and high porosity have attracted great research interest because of their high specific surface area and superhydrophobic properties. ${ }^{15-17}$ Their excellent accessibility to the inner surface through open

School of Chemical Engineering, Changchun University of Technology, Changchun 130012, P. R. China. E-mail: cclzy2001@163.com; Tel: +86-431-85716328

$\dagger$ Electronic supplementary information (ESI) available: SEM images, experimental parameters of silica aerogels. See DOI: 10.1039/c6ra26831e porous networks leads to unique properties, making them a promising candidate for various applications in wastewater treatment such as adsorbents of toluene, adsorbents of xylenes, ${ }^{\mathbf{1 8}}$ and adsorbents of heavy metal ions ${ }^{\mathbf{1 9}}$ and cleanup of oil spills.. ${ }^{2021}$ Among these potential applications, superhydrophobic silica aerogels can be flexibly utilized as absorbent materials to selectively absorb oil. Effective separation of oil from water is an important challenge for saving endangered environments, especially in cases of marine oil pollution.

Recent studies have established that the incorporation of polymers into silica aerogels is a more promising approach for this behavior because of the mechanical strength enhancement they afford, and the possibility of the polymer imparting hydrophobicity and thermal stability to the silica backbone. ${ }^{22,23}$ Kanamori ${ }^{\mathbf{2 5 , 2 6}}$ reported ambient pressure-dried, flexible, marshmallow-like aerogels with a bendable feature using methyltrimethoxysilane (MTMS) and dimethyldimethoxysilane (DMDMS) as co-precursors. However, the brittleness limits its non-load-bearing structural applications; recent efforts have been made to produce fiber-reinforced aerogel composites with higher strength. ${ }^{29}$ Since then, researchers determined the Young models of organic-inorganic hybrid aerogel/wollastonite composites at room temperature, and found that Ti incorporation into inorganic aerogels networks increases their Young's modulus. ${ }^{22}$ Research by $\mathrm{RaO}^{24}$ indicated that the mechanical strength of ceramic fiber reinforced aerogel insulation composites was greatly increased compared to pure silica aerogels. Meador ${ }^{27}$ reported the first synthesis of polyimide aerogels cross-linked through a polyhedral oligomeric silsesquioxane, octa(aminophenyl)silsesquioxane (OAPS). Then, 


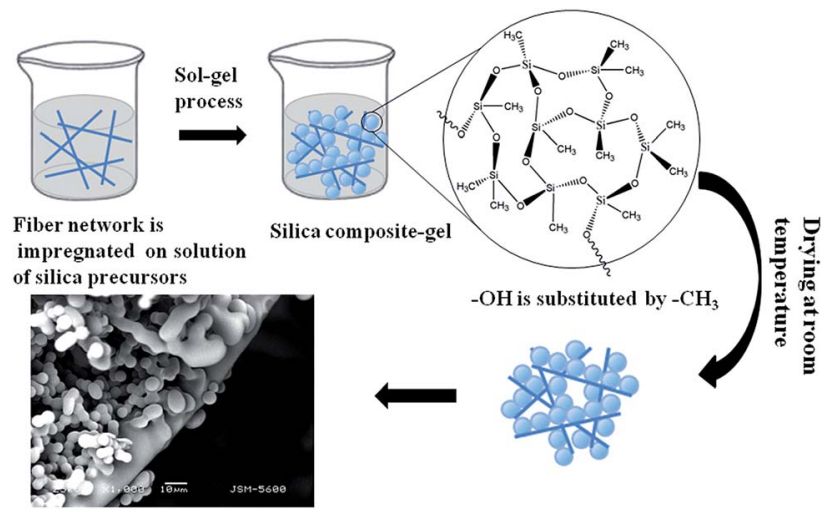

Scheme 1 Schematic for the synthesis of silica aerogels.

cellulose nanocrystals derived from tunicates (t-CNC) were used as reinforcing nanofiller for polyimide aerogels in their study for better moisture resistance, flexibility, and strength. ${ }^{32-34}$ Proper selection of silane precursors and polymer reinforcements can yield more durable and stronger silica aerogels. $\mathrm{Jana}^{28}$ focused on the use of silane-end-capped urethane prepolymer and chain-extended polyurethane for reinforcement of silica aerogels. They also produced silica gels grown inside the macropores of thermoreversible syndiotactic polystyrene (sPS) gel. ${ }^{30}$ Shengyang Tao prepared monolithic silica with macroporous skeleton that the maximum absorptive ability can reach 8 times the monolith's weight and materials could be recycled more than 20 times by an easy treatment. ${ }^{43}$ Xiangli Chen reported porous polymeric composite monoliths with superior performances the adsorption capacities of the porous materials that the maximum adsorption capacity of already-used transformer oil is $4.91 \mathrm{~g} / \mathrm{g}$ and the sorption and desorption process could be repeated at least 13 times. $^{44}$

Herein, we report a simple, low-cost, flexible, environmentallyfriendly approach for the synthesis and application of silica aerogels capable of separating oil from water in an easy, rapid manner ideal for practical applications. Scheme 1 details the preparation of the polyacrylonitrile fiber reinforced silica aerogels used in this study. This silica aerogel exhibits ideal superhydrophobic and mechanical strength. In the case of silica aerogels, the $\mathrm{Si}-\mathrm{OH}$ groups at the surfaces of the silica clusters are the main source of hydrophilicity, promoting condensation reactions. ${ }^{35}$ Our group previously determined that the $-\mathrm{Cl}$ in trimethylchlorosilane (TMCS) reacts with $-\mathrm{OH}$ to improve the hydrophobicity of the material. ${ }^{31,36}$ As shown in Scheme 1, the organic silicon source was hydrolyzed at $30^{\circ} \mathrm{C}$. The hydrogel then formed aerogel micro-granules and was aged at $40^{\circ} \mathrm{C}$. Finally, the wet gel was dried at ambient pressure after solvent replacement and modification of the surface hydrophobicity.

\section{Experimental section}

\section{Materials}

MTMS, DMDMS, $N, N$-dimethylformamide (DMF), and TMCS were provided by Xiya Reagent. Methanol, acetic acid and isopropanol were purchased from Shenyang Chemical Co. Ltd.
Ammonia and $n$-hexane was purchased from Beijing Chemical Works.

\section{Synthesis of polyacrylonitrile fibers}

Long polyacrylonitrile fibers were immersed in methanol or ethanol, followed by washing with ultrasonication for $10 \mathrm{~min}$, after which the solution was decanted and placed in an oven to dry. The polyacrylonitrile fibers used in the study is derived from the laboratory preparation. The fibers had a diameter of 10 $\pm 2 \mu \mathrm{m}$ and a length of $50 \mathrm{~mm}$.

\section{Synthesis of silica aerogel}

The silica aerogels was prepared by an acid-base two-step solgel method. MTMS (99\%), DMDMS (98\%), methanol (99\%), DMF (99.5\%), $\mathrm{H}_{2} \mathrm{O}$ and acetic acid (99\%) were stirred at a molar ratio $1: 0.7: 12: 0.5: 40: 7 \times 10^{-3}$ (Fig. S1, S2 and Table S1†) for $1 \mathrm{~h}$ at room temperature (approximately $30{ }^{\circ} \mathrm{C}$ ). $\mathrm{NH}_{3} \cdot \mathrm{H}_{2} \mathrm{O}$ (28\%) was added to set the pH of the MTMS stock solution at 89 (Fig. S3†) to control the condensation reaction. The prepared polyacrylonitrile fibers were then dispersed in solution and heated at $40{ }^{\circ} \mathrm{C}$ to induce gelation. The prepared silica aerogel was placed in isopropyl alcohol for $6 \mathrm{~h}$ at $40^{\circ} \mathrm{C}$ to remove water and unreacted reagents and to strengthen the aerogel network by aging. $10 \mathrm{vol} \%$ TMCS $(99.7 \%) / n$-hexane $(99 \%)$ was added to the wet gel and mixed at $40^{\circ} \mathrm{C}$ for $6 \mathrm{~h}$ (Fig. S4 $\dagger$ ). After this time, the residual mixture solution of the modified aerogel was poured out. The pore liquids in the wet gel were exchanged with isopropanol (99\%) and $n$-hexane $(99 \%)$ at $40{ }^{\circ} \mathrm{C}$ for $6 \mathrm{~h}$ in a shaker, reducing the surface tension. Finally, the mixture solution was removed and the aerogel was dried at $30^{\circ} \mathrm{C}$ under ambient pressure for $12 \mathrm{~h}$ to obtain products with different shapes.

\section{Characterization}

For all characterizations performed in this study, the fiber contents of the tested samples were $0 \%$ and $0.3 \%$ (mass fraction) (Fig. S10†).

The microstructure of the material was characterized by scanning electron microscopy (SEM), with a JSM-5600LV setup (JEOL, Japan). Prior to SEM imaging, samples were coated with gold through a $2-3$ min spraying process under vacuum. The hydrophobicity and surface modification were confirmed by Fourier transform infrared spectroscopy (FTIR). Here, samples were prepared without fibers to prevent the fiber groups from influencing the results. All measurements were performed at room temperature. FT-IR spectra $\left(4000-500 \mathrm{~cm}^{-1}\right)$ in $\mathrm{KBr}$ were collected on a Nicolet iS10 (Thermo Fisher, USA) FT-IR spectrometer by a $\mathrm{KBr}$ disc method. Contact angles of the aerogels were measured using a sessile method with a contact angle meter (Beijing Hakko test instrument factory, China). Aerogel samples were heat-treated at various temperatures of $30-600{ }^{\circ} \mathrm{C}$ in STA 6000 (Perkin Elmer, USA), and illustration thermogravimetric (TG) curves of the aerogel samples were measured to confirm their thermal stability. The mass of each sample was approximately $4 \mathrm{mg}$. TG analysis (TGA) tests were run at a temperature ramp rate of $10{ }^{\circ} \mathrm{C} \mathrm{min}{ }^{-1}$, and under $\mathrm{N}_{2}$ gas flow 
of $100 \mathrm{~mL} \mathrm{~min}^{-1}$. The pore volume and macro-porosity of the modified materials were determined using $\mathrm{Hg}$ intrusion porosimetry (Micromeritics Autopore IV 9500, USA) in a pressure range of 0.10-30 000 psi.

The bulk densities $\left(\rho_{\mathrm{b}}\right)$ of the prepared aerogels were calculated as function of on the gel mass-to-volume ratio. The skeletal density $\left(\sim 1.67 \mathrm{~g} \mathrm{~cm}^{-3}\right)$ was tested by helium pycnometry, and the porosities were calculated as

$$
\text { Porosity }=\left(1-\frac{\rho_{\mathrm{b}}}{\rho_{\mathrm{s}}}\right) \times 100 \%
$$

where $\rho_{\mathrm{b}}$ and $\rho_{\mathrm{s}}$ are the densities of the bulk and the skeleton of the aerogels, respectively.

The adsorption capacity of the aerogels for various organic solvents and oils was also measured. Aerogels were placed inside the organic liquids for approximately $10 \mathrm{~min}$ and then isolated for weight measurements. To avoid evaporation of absorbed organic liquids, weight measurements were performed immediately after adsorption. Each organic liquid was tested three times, and the mean weight gain was reported. To test the reusability, a wet aerogel was squeezed as hard as possible to get rid of the oil absorbed. The monolith was then extruded completely. Finally, there generated porous aerogel was reused and selective adsorption of oil from water.

Compression tests were carried out on the aerogel monoliths in two steps. First, the aerogels were compressed to $80 \%$ strain. The test was then stopped and the crosshead was moved back to zero. The specimen was then left to sit for $30 \mathrm{~min}$ at room temperature. At that time, the final thickness was measured and the unrecovered strain (\%) was determined as the amount of strain still present in the sample relative to the sample's initial length.

\section{Results and discussion}

\section{Characterization}

Low density aerogel was synthesized (Fig. S5 $\dagger$ ) at a density of $0.086 \mathrm{~g} \mathrm{~cm}^{-3}$, and the porosity was calculated as $95 \%$. These density and porosity values clearly indicate that the network structure was maintained after the drying process. The bending and flexibility of the as-prepared aerogel is demonstrated in Fig. S6. $\dagger$

The microstructures of the aerogels reinforced with polyacrylonitrile fiber are indicated by SEM in Fig. 1 (the unmodified aerogels are showed in Fig. S7, $\dagger$ fibers are in Fig. S11 $\dagger$ ). The diameter of the aerogel particle is mainly distributed between 4.4 and $5.8 \mu \mathrm{m}$ (Fig. 1c) from the SEM image of the aerogels. The particle size is uniform and the particle surfaces are smooth. The polyacrylonitrile fibers in the aerogel systems are quite effective in increasing the mechanical properties of aerogels. The fibers support the aerogel and decrease the bulk size of the aerogel within the aerogel-fiber matrix composite. Introducing a sol into a fibrous batting network allows it to gel and perform drying. Aerogels reinforced with polyacrylonitrile fiber networks show highly porous structures. $^{37}$ Thus, the prepared silica aerogel should simultaneously exhibit better strength and mechanical performances.

In the unmodified aerogel, an obvious $-\mathrm{OH}$ peak at 3500 $\mathrm{cm}^{-1}$ indicates that a significant fraction of the Si atoms exist as
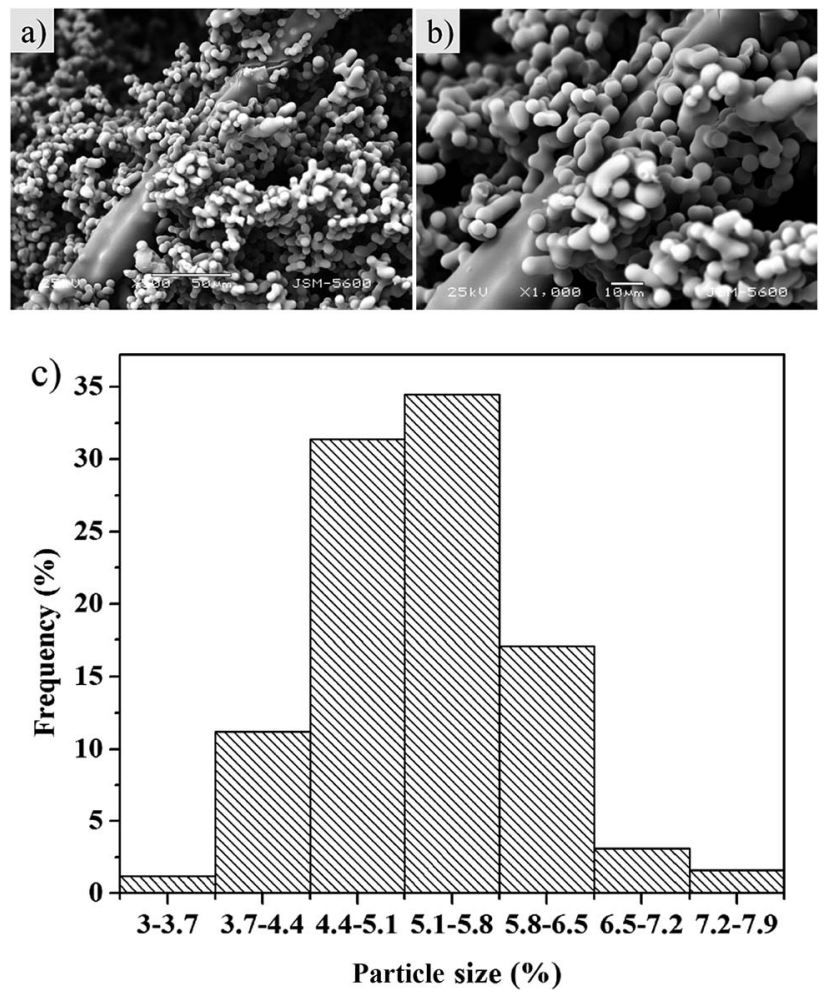

Fig. 1 SEM images of the aerogel with $0.3 \%$ fibers at different magnifications ( $a$ and $b$ ) and the particle size distribution of aerogel (c).

hydroxylated species on the surface in a gel network (Fig. 2). During the drying process at ambient pressure, these surface groups react to produce $\mathrm{Si}-\mathrm{O}-\mathrm{Si}$ bonds by condensation. The formation of $\mathrm{Si}-\mathrm{O}-\mathrm{Si}$ bonds collapses the pore network of the wet gel because of the high capillary pressures induced. ${ }^{38}$ The bands around $1096 \mathrm{~cm}^{-1}$ indicate $\mathrm{Si}-\mathrm{O}-\mathrm{Si}$ stretching vibrations, while the features around $798 \mathrm{~cm}^{-1}$ arise from $\mathrm{Si}-\mathrm{O}$ vibrations.

a)

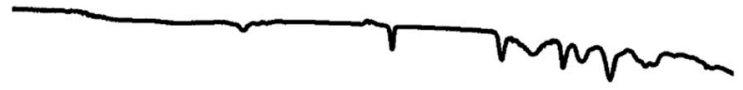

b)

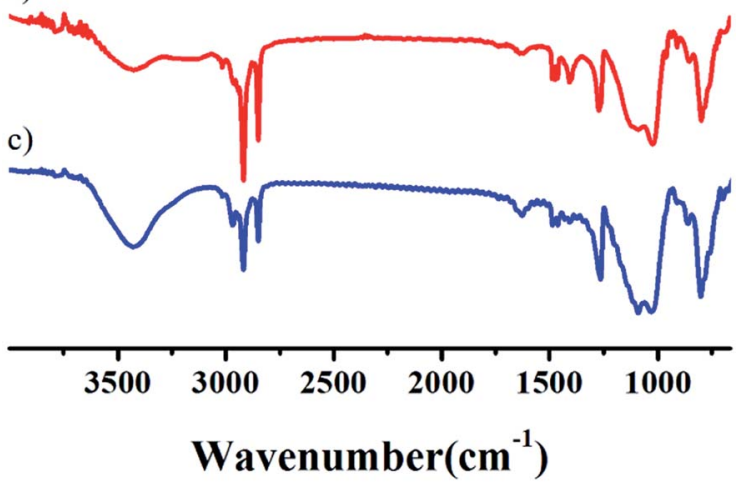

Fig. 2 FTIR spectra of aerogels at the following compositions: (a) fibers, (b) aerogel with fiber content is $0.3 \%$, (c) the unmodified aerogel. 

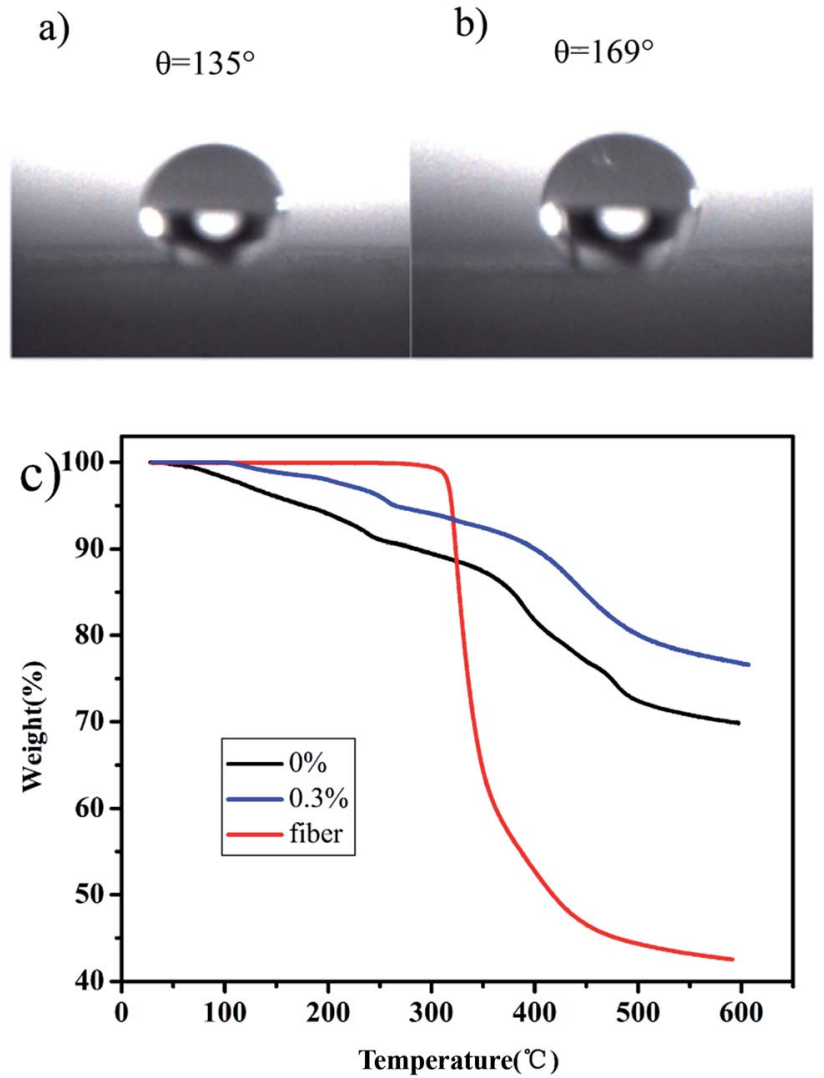

Fig. 3 The contact angles of unmodified (a) and modified aerogels (b). TG curves of aerogels with different fiber contents and fiber (c).

The adsorption bands at $3435 \mathrm{~cm}^{-1}$ can be assigned to hydroxyl groups. The peaks at around $2981-2900 \mathrm{~cm}^{-1}$ corresponded to $\mathrm{C}-\mathrm{H}$ and $\mathrm{CH}_{3}$ bands, the main source of hydrophobicity. As can be seen the infrared spectra of the $\mathrm{SiO}_{2}$-modified aerogel, the $\mathrm{H}-\mathrm{OH}$ peaks near 3425 and $1633 \mathrm{~cm}^{-1}$ are weakened to a certain degree, which can be explained by the aerogel modification. After being modified by TMCS, hydroxyl groups are substituted by $-\mathrm{CH}_{3}$ groups, resulting in more pronounced hydrophobic properties. Surface reactions occur homogeneously throughout the wet gel by diffusion along its open pore structure. That is, on the aerogel surface, hydroxyl $(-\mathrm{OH})$ or alkoxy $(-\mathrm{OR})$ groups were switched to stable SiR group, as verified from the thermogravimetric curve of the aerogel. The polyacrylonitrile fibers are added prior to the solution gel, where the fibers act merely as support frames for the gel. The fiber does not react chemically with the solution. Correspondingly, there is no chemical bond or chemical group change when aerogel is toughened by adding fiber. It can be seen that there is no large fluctuation in FTIR spectra with the exception of $\mathrm{O}-\mathrm{H}$ or $\mathrm{O}-\mathrm{R}$ and $\mathrm{C}-\mathrm{H}$ peaks. Both the modified and unmodified aerogels are still typical amorphous materials, as shown in Fig. S9.†

The contact angle of the unmodified aerogel was measured as $>130^{\circ}$. In Fig. $3 a$, this value is $136^{\circ}$ and can reach as high as $168^{\circ}$ in Fig. 3b, which is considered superhydrophobic ${ }^{39}$ and suitable for the separation of oil-water mixtures. Fig. 3c shows that the aerogel weight reduction is mainly divided into three
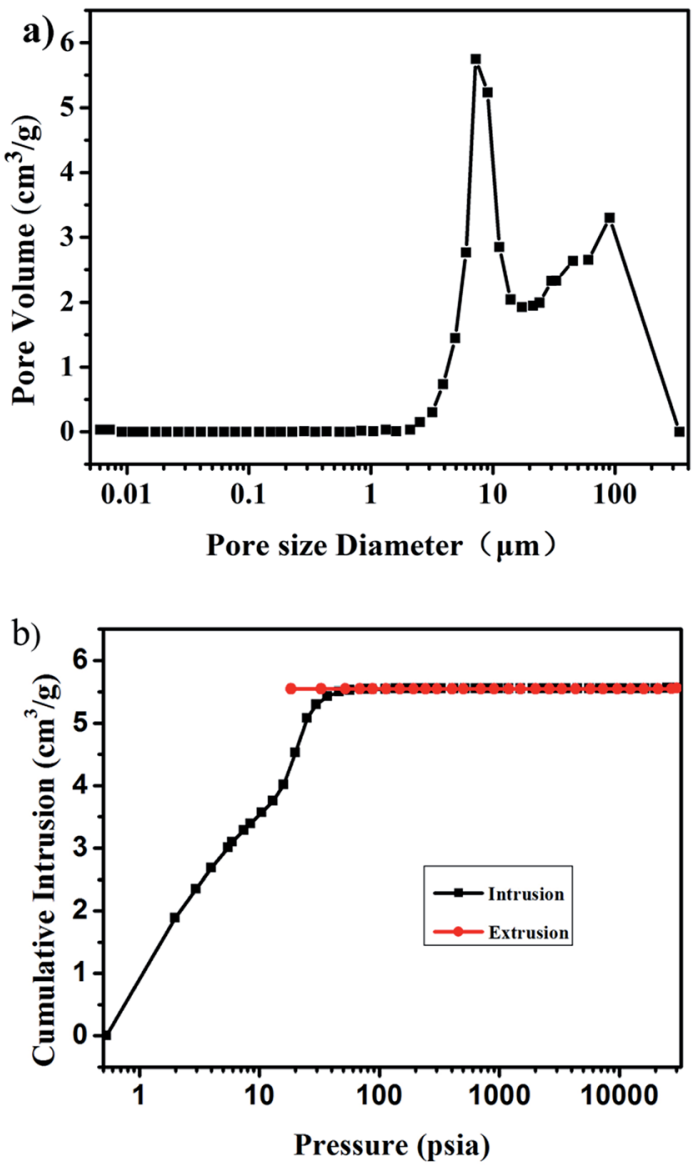

Fig. 4 Pore size distribution of the aerogel with $0.3 \%$ fibers (a) and the cumulative intrusion as a function of pressure (b).

stages. In both cases, loss occurred between $20-290{ }^{\circ} \mathrm{C}$ corresponding to the evaporation and dissociation of unreacted water and organic solvents. In the second step, the major weight loss appears between $290-600{ }^{\circ} \mathrm{C}$, as a result of severe $-\mathrm{CH}_{3}$ oxidation during the modification process. $\mathrm{SiO}_{2}$ residues were also present. ${ }^{40}$ The addition of fibers did not have much effect on the test results due to the low content of fibers in the aerogel. The aerogel with $0 \%$ fibers had a total mass loss of $30 \%$, while that of the aerogel with $0.3 \%$ fibers was $22 \%$.

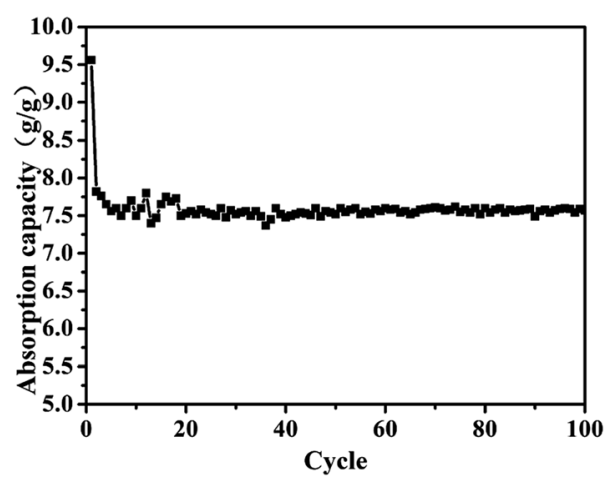

Fig. 5 Weight gain during diesel oil adsorption/drying cycles. 


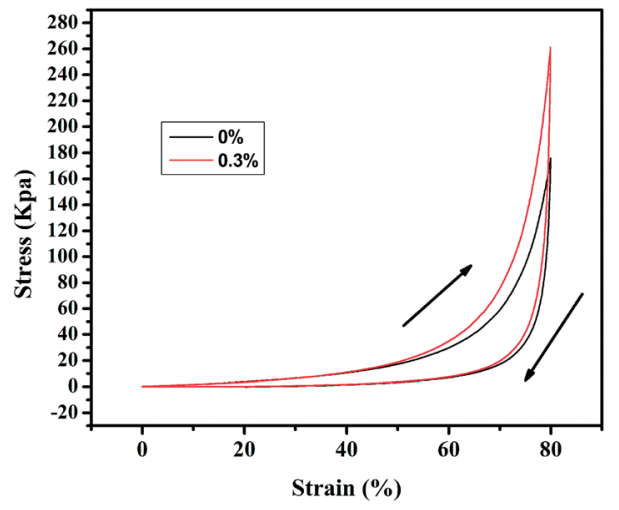

Fig. 6 Stress-strain curves of the aerogel with different fiber contents.

Quantitative analysis of the large-pore systems present in the aerogels (volume, size distribution) is scarcely possible from the nitrogen physisorption data alone, and therefore mercury intrusion porosimetry measurements were performed to determine the porosity within the aerogel monoliths. ${ }^{41}$ As measured by $\mathrm{Hg}$ intrusion porosimetry, the sizes of the macropores are mainly distributed in the range of 5-20 $\mu \mathrm{m}$, with a maximum value of approximately $8 \mu \mathrm{m}$ (Fig. 4a). The Brunauer-Emmett-Teller (BET) surface area of the aerogel is approximately $230 \mathrm{~m}^{2} \mathrm{~g}^{-1}$. The total intrusion volume of the aerogel is approximately $5.56 \mathrm{~cm}^{3} \mathrm{~g}^{-1}$ as shown in Fig. $4 \mathrm{~b}$.

\section{Adsorption experiments}

The aerogels' capacity to absorb diesel oil is indicated by the weight gain plotted in Fig. 5. To appraise the material as an oil/ water separation medium, we tested its absorbing-squeezing circulation behavior using diesel oil as a model organic compound. The performance of the adsorbent was tested by a simple immersion-extrusion method. In the first cycle, the aerogel is clean when immersed. However, a small portion of the diesel fuel sticks to the aerogel because of its half-sticky during extrusion and the aerogel was then extruded completely without drying. ${ }^{45}$ These cause a decrease in the absorption capacity for the second cycle. In the following cycles, the absorption capacity will be a small range of fluctuations due to the operation of the extrusion error. But in the end it will stabilize. Over one hundred cycles, the aerogel showed stable behavior; the aerogel adsorbs $7.5 \times$ its dry weight in diesel oil, and no damage is observed.

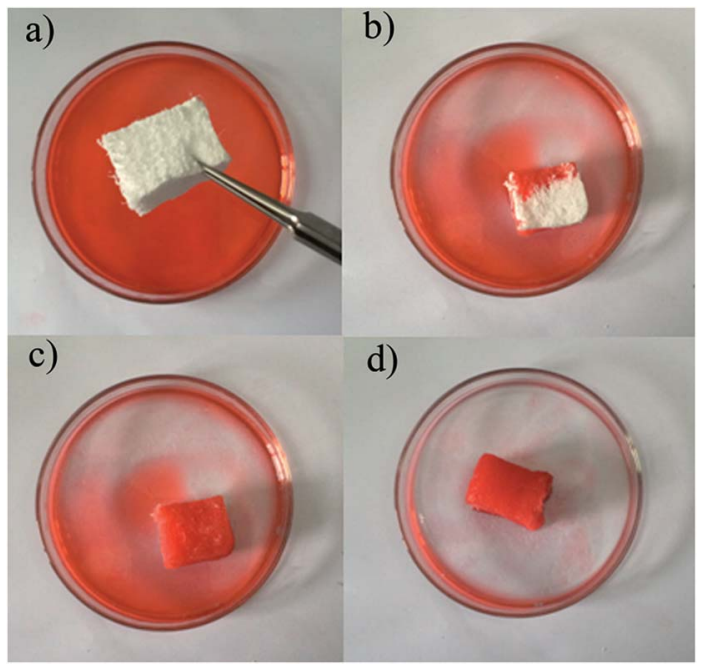

Fig. 8 Adsorption of diesel oil by the aerogel with $0.3 \%$ fibers.

Stress-strain curves were obtained from compression testing of the aerogels as shown in Fig. 6 (the flexibility of the modified aerogels is shown in Fig. $\mathrm{S} 8 \dagger$ ). Complete recovery was observed after $40 \%$ compression, with an approximate modulus of 260 $\mathrm{kPa}$ for the aerogel with $0.3 \%$ fibers and approximately $180 \mathrm{kPa}$ for the aerogel without fiber, demonstrating a linear elastic region up to approximately $80 \%$ strain.

Diesel oil removal tests were also performed in this work to investigate the ability of the aerogel to separate and adsorb diesel oils (Fig. 7 and 8). Almost all of the diesel oil was successfully separated in a rapid manner within 1 min of exposure. For the separation of oil and water system of the adsorbent, oil-water selectivity is through the contact angle test to evaluate. Many researchers have demonstrated the contact angle of more than $150^{\circ}$ indicates that the material has superhydrophobicity and good selectivity to oil and water through their researches and little adsorption of water is almost negligible. ${ }^{\mathbf{4 6 7}}$ It can be seen that water is not adsorbed by aerogel in Fig. S12a $\uparrow$ and aerogel floating on the water in Fig. S12b. $\dagger$ Due to the low mean density, the aerogel floated on the upper part of water and oil mixtures after the diesel oil was extracted completely, indicating that the system designed in this study is feasible for use in chemical spillages and elimination of oil leaks. Thus, these aerogels show great promise in separating

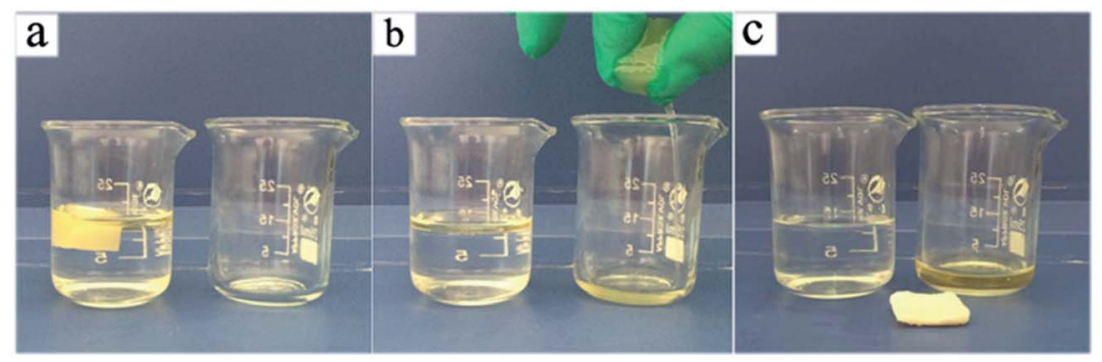

Fig. 7 Images depicting the flexibility of the aerogel with $0.3 \%$ fibers $(a, b$ and $c)$. 


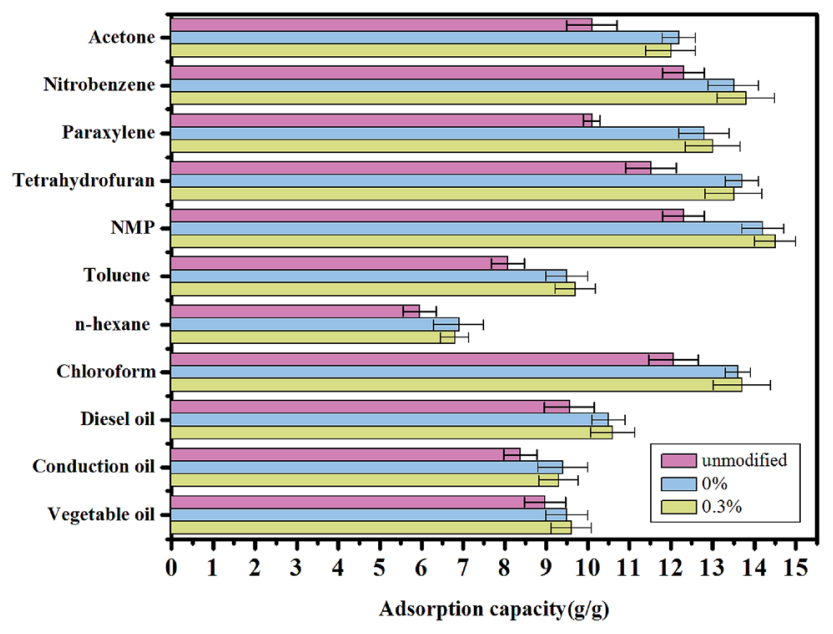

Fig. 9 Adsorption capacities of the aerogels with different fiber contents and unmodified for various organic solvents and oils, as indicated by weight gain.

dirt and oils from water due to their hydrophobicity, mechanical consistency and high porosity.

The aerogels were further tested by examining their adsorption for different organic pollutants. ${ }^{42}$ Different aerogels had different adsorption capacity for various organic pollutants when modified or unmodified, which all exceeded $6 \mathrm{~g} / \mathrm{g}$ (Fig. 9). The addition of fiber did not affect the structure of the material, so the adsorption performances of aerogel with and without fibers have a little difference. Compared with other organic pollutants, the aerogel with $0.3 \%$ fibers showed the greatest adsorption capacity for $N$-methyl-2-pyrrolidone (NMP), with a value of $14.7 \mathrm{~g} / \mathrm{g}$. The adsorption capacity of aerogel did not change much, fluctuating about $0.2-0.6 \mathrm{~g} / \mathrm{g}$ whether or not adding fiber. The organic molecules stockpile in the network structure of the aerogel and the weight ratio of absorbed solvent/dried gel depends on the density, viscosity, and surface tension of the absorbed liquids.

\section{Conclusions}

We reported a novel silica aerogel material for oil adsorption from oil/water mixtures, using a preparation method that is relatively simple, economic, and environmentally friendly. This preliminary study indicates that polyacrylonitrile fibers are promising candidates as reinforcing additives to silica aerogels. The polyacrylonitrile fibers were successfully incorporated into the silica matrix with good dispersion, with an approximate modulus of $260 \mathrm{kPa}$ for the aerogel with $0.3 \%$ fibers, indicating that polyacrylonitrile fibers reinforced the silica aerogels and improved their strength. At the same time, hydrophobic modification of the aerogel led to a water contact angle as high as $169^{\circ}$. The modified aerogels has obviously enhanced adsorption capacity and oil-water separation effects. Moreover, the superhydrophobic silica aerogel exhibits high oil-absorbing efficiency and could be directly applied to the water treatment industry.

\section{Acknowledgements}

This research was financially supported by the Science and Technology Program Project of Jilin Province of China (No. 20130206069SF, 20150520012JH, 20160101322JC) and the Education Department of Jilin Province (No. 2016350).

\section{References}

1 M. O. Adebajo, R. L. Frost, J. T. Kloprogge, O. Carmody and S. Kokot, J. Porous Mater., 2003, 10, 159-170.

2 M. Toyoda and M. Inagaki, Carbon, 2000, 38, 199-210.

3 Q. Zhu, F. Tao and Q. M. Pan, ACS Appl. Mater. Interfaces, 2000, 2, 3141-3146.

4 Q. Wei, R. Mather, A. Fotheringham and R. Yang, Mar. Pollut. Bull., 2003, 46, 780-783.

5 L. Feng, Z. Zhang, Z. Mai, Y. Ma, B. Liu, L. Jiang and D. A. Zhu, Angew. Chem., Int. Ed., 2004, 43, 2012-2014.

6 D. Ceylan, S. Dogu, B. Karacik, S. D. Yakan, O. S. Okay and O. Okay, Environ. Sci. Technol., 2009, 43, 3846-3852.

7 H. C. Bi, X. Xie, K. B. Yin, Y. L. Zhou, S. Wan, L. B. He, F. Xu, F. Banhart, L. T. Sun and R. S. Ruoff, Adv. Funct. Mater., 2012, 12, 4421-4425.

8 Q. Zhu, Q. M. Pan and F. T. Liu, J. Phys. Chem. C, 2011, 115, 17464-17470.

9 X. C. Dong, J. Chen, Y. W. Ma, J. Wang, M. B. Chan-Park, X. M. Liu, L. H. Wang, W. Huang and P. Chen, Chem. Commun., 2012, 48, 10660-10662.

10 X. Y. Zhang, Z. Li, K. S. Liu and L. Jiang, Adv. Funct. Mater., 2013, 22, 2881-2886.

11 A. Li, H. X. Sun, D. Z. Tan, W. J. Fan, S. H. Wen, X. J. Qing, G. X. Li, S. Y. Li and W. Q. Deng, Energy Environ. Sci., 2011, 4, 2062-2065.

12 G. Hayase, K. Kanamori, M. Fukuchi, H. Kaji and K. Nakanishi, Angew. Chem., Int. Ed., 2013, 52, 1986-1989.

13 X. T. Zhu, Z. Z. Zhang, G. N. Ren, J. Yang, K. Wang, X. H. Xu, X. H. Men and X. Y. Zhou, J. Mater. Chem., 2012, 22, 2014620148.

14 T. Woignier, J. Reynes, A. Hafidialaoui, I. Beurroiesm and J. Phalippou, J. Non-Cryst. Solids, 1998, 241, 45-52.

15 Y. Li, W. P. Cai, B. Q. Cao, G. T. Duan, F. Q. Sun, C. C. Li and L. C. Jia, Nanotechnology, 2006, 17, 238-243.

16 D. A. Doshi, P. B. Shah, S. Singh, E. D. Branson, A. P. Malanoski, E. B. Watkins, J. Majewski, F. Swol and C. J. Brinker, Langmuir, 2005, 21, 7805-7811.

17 N. Leventis, C. Chidambareswarapattar, A. Bang and C. Sotiriou-Leventis, ACS Appl. Mater. Interfaces, 2014, 6, 6872-6882.

18 G. T. Qin, Y. Yao, W. Wei and T. Zhang, Appl. Surf. Sci., 2013, 280, 806-811.

19 C. M. Wang, K. S. Chang, T. W. Chung and H. D. Wu, J. Chem. Eng. Data, 2004, 49, 527-531.

20 M. L. N. Perdigoto, R. C. Martins, N. Rocha, M. J. Quina, L. Go-Ferreira, R. Patrício and L. Durães, J. Colloid Interface Sci., 2012, 380, 134-140.

21 J. W. Tana, W. Sub, T. J. Doub and X. P. Fana, Sep. Sci. Technol., 2012, 47, 1149-1155. 
22 J. Cai, S. Liu, J. Feng, S. Kimura, M. Wada, S. Kuga and L. Zhang, Angew. Chem., Int. Ed., 2012, 51, 2076-2079.

23 M. A. B. Meador, Aerogels Handbook, Springer, 2011, part V, pp. 315-334.

24 V. A. Rao, S. D. Bhagat, H. Hirashima and G. Pajonk, J. Colloid Interface Sci., 2006, 300, 279-285.

25 G. Hayase, K. Kanamori and K. Nakanishi, J. Mater. Chem., 2011, 21, 17077-17079.

26 G. Hayase, K. Kanamori, K. Kazuki and T. Hanada, IOP Conf. Ser.: Mater. Sci. Eng., 2011, 18, 032013.

27 H. Q. Guo, M. A. B. Meador, L. McCorkle, D. J. Quade, J. Guo, B. Hamilton, M. Cakmak and G. Sprowl, ACS Appl. Mater. Interfaces, 2011, 3, 546-552.

28 X. Wang and S. C. Jana, ACS Appl. Mater. Interfaces, 2013, 5, 6423-6429.

29 I. A. Sacui, R. C. Nieuwendaal, D. J. Burnett, S. J. Stranick, M. Jorfi, C. Weder, E. J. Foster, R. T. Olsson and J. W. Gilman, ACS Appl. Mater. Interfaces, 2014, 6, 6127-6138.

30 Y. N. Duan, S. C. Jana, A. M. Reinsel, B. Lama and M. P. Espe, Langmuir, 2012, 28, 15362-15371.

31 D. B. Mahadika, A. V. Raoa, A. P. Raoa, P. B. Waghb, S. V. Ingaleb and S. C. Guptab, J. Colloid Interface Sci., 2011, 356, 298-302.

32 B. N. Nguyen, E. Cudjoe, A. Douglas, D. Scheiman, L. McCorkle, M. A. B. Meador and S. J. Rowan, Macromolecules, 2016, 49, 1692-1703.

33 M. A. B. Meador, C. R. Alemán, K. Hanson, N. Ramirez, S. L. Vivod, N. Wilmoth and L. McCorkle, ACS Appl. Mater. Interfaces, 2015, 7, 1240-1249.
34 H. Q. Guo, M. A. B. Meador, L. McCorkle, D. J. Quade, J. Guo, B. Hamilton and M. Cakmak, ACS Appl. Mater. Interfaces, 2012, 4, 5422-5429.

35 Y. N. Duan, S. C. Jana, B. Lama and M. P. Espe, Langmuir, 2013, 29, 6156-6165.

36 A. V. Rao, D. P. Kulkami and T. Seth, Appl. Surf. Sci., 2003, 206, 262-270.

37 S. W. Hwang, T. Y. Kim and S. H. Hyun, J. Colloid Interface Sci., 2008, 322, 224-230.

38 M. Kanedal, O. Terasaki, D. Y. Zhao, J. M. Kim, G. Stucky, H. J. Shin and R. Ryoo, Nature, 2000, 408, 449-453.

39 Z. T. Mazraeh-shahi, A. M. Shoushtari, A. R. Bahramian and M. Abdouss, Fibers Polym., 2014, 15, 2154-2159.

40 K. M. Aizawa, K. Nakanishi and T. Hanada, Adv. Mater., 2007, 19, 1589-1593.

41 F. Irin, S. Das, F. O. Atore and M. J. Green, Langmuir, 2013, 36, 11449-11456.

42 J. M. Al-Besharah, O. A. Salman and S. A. Akashah, Ind. Eng. Chem. Res., 1987, 12, 2445-2449.

43 S. Y. Tao, Y. C. Wang and Y. L. An, J. Mater. Chem., 2011, 21, 11901-11907.

44 X. L. Chen, L. L. Liu, K. Q. Liu, Q. Miao and Y. Fang, J. Mater. Chem. A, 2014, 2, 10081-10089.

45 S. Venkatanarasimhan and D. Raghavachari, J. Mater. Chem. A, 2013, 1, 868-876.

46 M. Patowary, K. Pathak and R. Ananthakrishnan, RSC Adv., 2015, 5, 79852-79859.

47 Z. X. Xue, Y. Z. Cao, N. Liu, L. Feng and L. Jiang, J. Mater. Chem. A, 2014, 2, 2445-2460. 